University of Nebraska - Lincoln

DigitalCommons@University of Nebraska - Lincoln

The Nebraska Educator: A Student-Led Journal Department of Teaching, Learning and Teacher

Education

Spring 10-26-2020

\title{
The History, Evolution, and Trends of Academic Dishonesty: A Literature Review
}

Amy Zachek

University of Nebraska-Lincoln, amyzachek@gmail.com

Follow this and additional works at: https://digitalcommons.unl.edu/nebeducator

Part of the Teacher Education and Professional Development Commons

Zachek, Amy, "The History, Evolution, and Trends of Academic Dishonesty: A Literature Review" (2020). The Nebraska Educator: A Student-Led Journal. 53.

https://digitalcommons.unl.edu/nebeducator/53

This Article is brought to you for free and open access by the Department of Teaching, Learning and Teacher Education at DigitalCommons@University of Nebraska - Lincoln. It has been accepted for inclusion in The Nebraska Educator: A Student-Led Journal by an authorized administrator of DigitalCommons@University of Nebraska - Lincoln. 


\title{
The History, Evolution, and Trends of Academic Dishonesty: A Literature Review
}

\author{
Amy Zachek \\ Department of Educational Administration \\ University of Nebraska-Lincoln
}

\begin{abstract}
Academic dishonesty is a murky problem without a commonly agreed upon solution in American higher education. It has a long-standing history in higher education but a short history in academic literature, it has evolved rapidly and longitudinally (McCabe \& Trevino, 1996), and it has several easily apparent trends and others that the majority of researchers are in disagreement about. While traversing this perilous landscape of dichotomies, this paper will examine connections and gaps in the literature, make suggestions and recommendations for future study based off of these results, and examine the implications that these recommendations could have on higher education policy. Results demonstrate that a learning-based, non-penal approach to academic dishonesty may be the most helpful stance that institutions can take for their students. Key areas of interest to the author include the intersections of technology, generational change, and self-authorship, and these areas will be focused on in detail throughout the literature review.
\end{abstract}

Keywords: college students, higher education, cheating, academic dishonesty, history, evolution, trends

doi: 10.32873/unl.dc.ne006 
In the realm of higher education, there is one cardinal sin above all others: academic dishonesty. After all, the theft of thought is antithetical to the entire institutional purpose of education. In reviewing the literature surrounding academic dishonesty, I will explore its historical context and the history of its presence in the literature, trace its evolution, and analyze contemporary trends. In the course of this chronological review, I will explore several pieces that are important to a richer understanding of this topic, including demographics, generational change, and technology. In this way, I will synthesize the history of academic dishonesty, how it has evolved, and its contemporary status in American higher education, and use that analysis to discover gaps, challenges, and implications for the future.

Throughout the course of this literature review, I will utilize the terms academic dishonesty and cheating. I define academic dishonesty as any act of cheating in isolation, collusion with other students, or plagiarism. Allemand (2012) broadly defines academic dishonesty as any sort of unfair academic advantage, and I agree with the spirit of this broad definition. For the purposes of this literature review, I consider academic dishonesty and cheating to be analogous terms and I will refer to the two interchangeably.

\section{History of Academic Dishonesty}

An immediate assumption one might make is that academic dishonesty is a recent phenomenon; an epidemic of modern society that did not affect our more morally austere predecessors. Chace (2012) illustrates that this is far from the case. He writes, "Indeed, every study over the decades has concluded that cheating at American colleges and universities is rampant" (Chace, 2012, p. 23). Ergo, cheating is not a problem that has cropped up in recent years; studies simply reaffirm time and time again that it exists. Echoing this sentiment, Arnold et al. (2007) write "Since the beginning of formalized education, student cheating has been a 
challenge for educators" (p. 2). In Blum's (2009) book “My Word! Plagiarism and College Culture," she delineates the colorful and varied history of cheating around the world. One of the oldest examples comes from China, where there was a 1400 year history of cheating for the keju exam for civil service (Blum, 2009). A startling example from the history of American higher education comes from Yale, when "cheating scandals involved half the student body at Yale in the 1860s" (Blum, 2009, p. 25). From these examples, it's easy to see that academic dishonesty is not a new problem.

\section{Literature Chronology}

Even with the lengthy history of academic dishonesty in education, the articles that I found for this review seem to suggest that literature in this area first originated in the twentieth century. Several authors consider Bowers' (1964) work to be the seminal, landmark academic study of academic dishonesty (Chace, 2012; McCabe \& Trevino, 1996). Chace (2012) writes that Bowers' work was the "first comprehensive study of cheating at colleges and universities" (p. 23). However, though Bowers' work may have been the first influential work in the field, it was by no means the first study of academic dishonesty. Bowers' (1964) study identifies several precursors to his research in the field, including a 1920s study about the causes of dishonesty, a 1935 study about honor systems, and the 1960 Cornell Value Study. The impressive thing about Bowers' (1964) study is that its scale was unprecedented in the field and that its findings are important enough to still be relevant to the field over 50 years after it was published.

One of Bowers' (1964) primary conclusions is that, at least according to one set of questions regarding academically dishonest behaviors, "fully three-quarters of the students have engaged in at least one act of academic dishonesty; half have committed two or more" (p. 48). Modern academic dishonesty does not look much different, and at least two studies since 1964 
have illustrated that cheating has only trended upward since the Bowers study (McCabe et al., 1996; McCabe \& Trevino, 2001). McCabe et al. (2001) state that "Cheating is prevalent and some forms of cheating have increased dramatically in the last 30 years" (p. 219). McCabe and Trevino (1996) don't necessarily claim a sharp uptick in cheating, but they describe a small and consistent increase since Bowers' cheating study (McCabe \& Trevino, 1996; Bowers, 1964). Recent works such as Tavris and Aronson's (2020) piece have gone beyond a demographic study of academic dishonesty and have attempted to explain why it may be easier for some students to participate in cheating behaviors than others. Tavris \& Aronson (2020) posit that students who have made the decision to cheat (or not cheat) are more resolute in their decision and belief system after they have made that choice, and that each future decision makes them feel even more resolute in their personal decisions. More future studies that examine the reasons why students cheat will be necessary to help provide insight on this topic.

\section{Evolution of Academic Dishonesty}

Over the last half century, one of the key ways that academic dishonesty has evolved is by way of changed generational attitudes. Blum (2009) does an excellent job describing some of the generational shifts which have created an ideal cultural temperature for academic dishonesty in academia today. She writes about the social shift from valuing an authentic self to valuing a performance self, and how that has had a critical impact on youth culture (Blum, 2009). Blum (2009) states, "If in the past a stable and integrated identity was regarded as the basis of mental health, in recent years a fluid, flexible self is seen as more responsive and more socially desirable" (p. 79). She then relates this idea to the traditional academic concepts of authorship and intellectual property, writing, "This self, made out of various readily available components, is as unconcerned about strict attribution of authorship as it is about strictly tracing an 
unchanging identity," (Blum, 2009, p. 79). In this way, this flexible self may have a greater impact on students' propensity to cheat than higher education administrators may realize (Blum, 2009)

\section{Technology}

This fluid identity may have partially come about due to modern technology, and the common concept of "identity play" in online gaming (Blum, 2009, p. 78). So, while online gaming doesn't directly interact with academic dishonesty, the effect that it may be having on student attitudes does. Hamlen's (2012) piece about video gameplay also discusses these changes in attitudes. Hamlen (2012) writes, "This study was based on the theory that current media-immersed children may think and learn differently than those in the past," (p. 1146). Though her results do not find strong evidence for her theory about video games affecting academic dishonesty, she does claim that "new technologies are enabling new ways of learning and thinking" (Hamlen, 2012, p. 1146).

When it comes to technology and cheating, the literature mainly seems to focus on the technology that assists cheating detection and not how students use technology to cheat. For example, Sledge and Pringle (2010) mention a few websites that help instructors fight cheating with technology, stating "In college, technology has allowed cheaters to be quickly identified through websites such as turnitin.com and essayrater.com" (p. 4-5). Blum (2009) goes into more detail about how students use technology to cheat. She writes about Wikipedia, but chooses to focus on how this is another platform which is shaping generational attitudes about cheating instead of the technological side of how students use it to cheat (Blum, 2009). She writes, "Wikipedia is one technological innovation that takes to its logical conclusion the general unconcern among the young about tracing individual contributions to a written product. This is 
regarded with great consternation by educational authorities, guided by their model of the authentic self" (Blum, 2009, p. 70). In this way, we can see that the intersection of ever-present technology and generational attitudes has had a powerful impact on the evolution of academic dishonesty.

\section{Trends in Academic Dishonesty}

\section{Us Vs. Them}

A key trend in the literature is the concept of the students vs. teachers or us vs. them (Helgeson, 2002; Wideman, 2011). One student in Helgeson's (2002) study incorporates this concept into their response about how faculty handle cheating, stating, "It's kind of like 'students vs. teachers' and we help each other out" (p. 124). With this divide between students and teachers, it makes sense that there are also correspondingly differing opinions about academic integrity policies from both students and faculty (Helgeson, 2002; Allemand, 2012). It's clear that finding a universal solution that all stakeholders agree upon is one challenge. Hamlen (2012) even goes so far as to suggest that the "disparity between student and teacher beliefs about what constitutes cheating" (p. 1146) is one of the main reasons for high rates of cheating. She also writes about nature versus nurture as initial factors that lead to cheating behaviors. Hamlen (2012) states that there are differing opinions in the field about whether environmental factors or the personality of the student is the cause of cheating.

\section{Honor Codes}

Arnold et al.’s (2007) piece about honor codes echoed Bowers' (1964) sentiments about climate by stating that "a culture of academic integrity may be the single most determining factor regarding student cheating on a college campus" (p. 3). Arnold et al. (2007) differ with Bowers (1964) in finding that there are not significantly lower amounts of cheating at schools with honor 
codes. Bowers (1964), on the other hand, writes that "Schools with honor systems have by far the lowest rate of academic dishonesty" (p. 184). It's important to note that Bowers' (1964) data and opinion on this subject is over fifty years old and could be outdated due to the different historical contexts in the period. For example, Bowers (1964) writes that honor systems were especially prevalent at single-sex schools, and it's possible that many of those institutions might have closed or substantially changed in the second half of the $20^{\text {th }}$ century due to the Civil Rights Act (1964). Regardless of the efficacy of honor codes, Arnold et al. (2007) show that these systems have returned to higher education in force in a (well-intentioned but potentially misguided) attempt to fight the prevalence of academic dishonesty.

\section{Social Changes}

Next, Blum's (2009) piece provides an anthropological look at student life and youth culture, and how that affects their outlook on academic integrity. Taking the stance of an ethnographer, Blum (2009) points out a number of social trends that she has observed. These observations include that the Generation $\mathrm{Y}$ and $\mathrm{Z}$ enjoy informal intertextuality, that students have been raised to be sociable, and that society has transitioned from valuing the authentic self to valuing the performance self (Blum, 2009). She describes that these attitudes of the younger generations are what have led to a "mismatch between the academy's and student's expectations" (Blum, 2009, p. 179). In this way, she shows that the new performance self directly contradicts age old ideas of authorship and intellectual property (Blum, 2009). Through these points, Blum (2009) illustrates social change as a trend in the recent years of academic dishonesty. She would likely suggest that academe is increasingly out of touch with a youth culture that values intertextuality, sharing, and communal authorship. 
An example of this cultural discrepancy can be found in Chace's (2012) essay. He states that "the essay's fingerprint" (Chace, 2012, p. 23) or its originality is the goal of academic writing. This thought process is in line with the old guard of the academy when one contrasts it against Blum's (2009) idea of the authentic self and authorship as irrelevant to the current generation. Interestingly, he is aware of the double-standards that today's youth experience with intertextuality and academic citing standards. Chace (2012) writes, "a wrong in one place is highly prized in another" (p. 26), a point which connects back with Blum's (2009) suggestion about everything relating to cultural relativism and shifted generational attitudes. Beasley (2016) also echoes these ideas in stating that in youth culture "sharing and quoting without attribution are established norms of conduct" (p. 56). He takes this a step further and writes that, "In addition to this hypersharing reality that many of today's college students live in, the students are also embedded in an overarching American culture where honesty does not seem very valued, especially when being dishonest can get one "ahead,"' (Beasley, 2016, p. 56). After all, if those are the norms that we are drilling into our youth, naturally they are going to demonstrate that societal training in their writing and work.

\section{External and Internal Values}

Another significant trend is the importance of the external value system on campus and students' internal values. Bowers (1964) writes "The combination of weak disapproval of cheating and poor grades results in more than four out of five students' being cheaters" (p. 78). He also uncovers the importance of internal values on cheating. If parents put importance on good grades, students are more likely to cheat; if students put more importance on good grades, they are less likely to cheat (Bowers, 1964). In other words, Bowers (1964) is suggesting that 
the desire to have good grades and to succeed must come from within; if that pressure comes from the outside, students may strive to achieve the grade at any cost to receive external praise.

\section{Demographics}

Beasley's (2016) article takes a look at the demographics of students who are reported for academic dishonesty. In line with the other research (Allemand, 2012), he writes that, "few official sanctions levied upon students for academic dishonesty" (Beasley, 2016, p. 45). In looking at the demographics of who cheats, one of Beasley's (2016) primary concerns is if students of minoritized racial backgrounds are more likely to be reported due to institutionalized racism. To this end, Beasley (2009) reports that, "International undergraduates were much more likely to get reported for academic dishonesty than were domestic students" (p. 55). At this time, there does not seem to be a clear answer for this difficult question, but this is an important area for future critical research.

When it comes to the demographics of gender, two studies are in agreeance that women students cheat less than men students (Bowers, 1964; Hamlen, 2012; Helgeson, 2002). However, these views are widely contested in other studies. Arnold et al. (2007) and Beasley (2016) find no gender differences when it comes to cheating, the latter also echoes the inconsistencies of findings and beliefs regarding gender and cheating in the literature. Beasley (2016) does bring up an interesting idea that originates from McCabe, which is that "the previously found gender differences in cheating behavior have diminished to being virtually nonexistent in the second decade of the 21 st century" (p. 49) and that that accounts for one explanation of the inconsistency with previous research findings. 
Many other demographics are at play besides gender. Once again, most of the literature seems to proffer its own views on the demographic characteristics of a student who cheats. Beasley (2009) lists the following as characteristics of students who are often caught cheating: The lower the GPA, the more likely it was that the student would be found guilty. In addition, non-Whites, students in fraternities or sororities, transfer students, and students who were not varsity athletes were more likely than their contemporaries to be found guilty. (p. 46)

Looking at the demographic of major, Sledge and Pringle (2010) find that there is "disproportional cheating by business students" (p. 5). More than anything, these disparate views show that students of any intersection of identities can commit an act of academic dishonesty.

\section{Gaps in the Literature}

Now that we have explored the history, evolution, and trends of academic dishonesty, let's look into the gaps in the literature. One self-admitted gap of Bowers' (1964) study is that it would be better to compare intellect ability to cheating, not just grades (GPA). He writes, "Instead, we must make do with the student's grades in college, which reflect not only his ability but also his motivation" (Bowers, 1964, p. 73). Another gap is the issue of self-reporting, which is a perennial issue for most all of the studies included (Blum, 2009; Sledge \& Pringle, 2010). To this end, Blum (2009) writes that "we can understand the students to be not exactly "telling the truth" but rather performing a virtuous - or daring - self in front of a peer interviewer" (p. 8).

Like Arnold et al. (2007), Sledge and Pringle (2010) also look at honor codes in their piece. Rather than just assessing the landscape of academic dishonesty, Sledge and Pringle (2010) take a slightly different approach by applying a set of interventions at their institution, 
studying their effect, and then applying a second set of interventions to try to create broad cultural change. In the end, they conclude that "students may be the best resource to teach their peers about the honor code" (Sledge \& Pringle, 2010, p. 9). Another gap is that their study was only held at their campus' business college A broader approach would be a better application of the efficacy of honor code interventions, particularly in combination with some of their recommendations of connecting with high school students and seeking college student buy-in up front (Sledge \& Pringle, 2010).

One gap in Chace's (2012) piece is that he does not seem to be familiar with the literature that shows that cheating happens in nearly equivalent amounts at colleges with and without honor codes (Arnold et al., 2007). Instead, he enshrines schools with honor codes as saviors of academic integrity, writing, "They see the dangers of cheating for what they are: practices in which many students can be hurt by the dishonesty of a few" (Chace, 2012, p. 31). Higher education administrations should take care to beware of wearing rose-colored glasses and to avoid an over-romanization of honor codes as an academic panacea.

Another gap, as pointed out by Beasley (2009), is the potential effect of racism on the reporting of students for academic dishonesty. A qualitative study with a critical theory approach on the effect of stereotypes and racist beliefs would be prudent. A parallel gap to this is research that explores if environmental factors or the personality of the student who cheats is a bigger cause of cheating behaviors. As explored earlier, Hamlen (2012) illustrates that there are differing opinions in the field on the subject, so this is definitely an area where additional research would help shed light on the subject. More research about the motivations for academic dishonesty in general would help inform academic dishonesty policy and ensure that institutional interventions are getting at the root cause of cheating on campus. 
Some consider differences in cheating in relation to gender to be outdated in our society where gender norms do not matter as much as they once did (Beasley, 2016). While it is true that gender norms have changed in American society, the literature I reviewed made no mention of cheating in relation to students who don't identify with the normative gender binary. Nonbinary, transgender, and other students were not even categorically mentioned in the literature I reviewed. This is certainly another gap and could also be a potential area for future inquiry, since I did not find literature to exist yet about academic dishonesty for this specific student population.

A final area for potential future study comes from a postulation in Bowers' (1964) study. He suggests that one possible ill-effect of academic dishonesty is that it may lead to professionals in the workplace who disregard ethics (Bowers, 1964). One potential recommendation for future research could be a study of ethics in the workplace for college cheaters vs. non-cheaters. Bowers (1964) already takes steps to analyze high school cheaters and how that affects cheating in college, and discovers that, "those most prone to cheat [in college] are those who cheated in high school and have been consistently socially oriented" (p. 137). It would be interesting to take this idea a step further and look at the correlation between college cheating and the workplace. Similarly to high school cheaters being more likely to cheat in college, are college cheaters more likely to continue their behaviors and to "cheat" (e.g. disregard ethics and the rules, do things out of personal gain, etc.) in the workplace? This current gap in the researcher would show the real-world importance of effectively intervening with academic dishonesty before students enter the workplace. 


\section{Recommendations}

It's clear from the literature that there are many divisive opinions about academic dishonesty, and that it's not a subject with clean-cut answers. Therefore, my two key recommendations are that more research is needed about student motivations and reasons for academic dishonesty and that an educational approach to responding to academic dishonesty is optimal. For the first recommendation, colleges and universities will never be able to appropriately respond to and stop academic dishonesty until they understand where their students are coming from (Kibler \& Kibler, 1993). In this way, I consider the heart of the academic dishonesty problem to be an issue of understanding which requires more research, educational initiatives, and dialogues between students and administrators.

Blum (2009) writes that academic integrity should not be viewed as an issue of morality or criminality. Instead, she proposes that "a third approach treats academic integrity, especially the mandate to cite sources, as a set of academic skills to be learned" (Blum, 2009, p. 165). In other words, frame this as a learning opportunity. Treat academic integrity like any other academic subject and teach students why it matters. This is also where researching and understanding more about student experiences, perceptions, and motivations of academic dishonesty will show results. Administrators will start to understand why cheating is happening in the first place and to create new programs to target these areas of student development. Students will understand why academic integrity is important by receiving formalized instruction about it, and administrators will be able understand the foundational reasons why students cheat and to provide the support that students need to eliminate cheating as a coping strategy. I postulate that this two-fold approach could be one way to approach solving the academic dishonesty problem on campus. 


\section{Conclusion}

In this literature review, I have synthesized the history and contemporary status of academic dishonesty in American higher education. I hope to have revealed patterns, gaps, and potential recommendations for higher education administrators and future study. The lenses of demographics, generational change, and technology provided helpful insights along the way, and I think that the intersection of each of these areas with academic dishonesty are their own rich areas of study. This field is particularly ripe for study since it is still a murky subject for colleges and universities without universally agreed upon solutions. One potential way to get to that point is to study the problem in greater detail, to create educational opportunities for students to learn more about how to create academic work with integrity, and to create opportunities for administrators to learn more about why students cheat. After all, in describing one example of a multiple offense cheater, Blum (2009) writes that the student "really wanted her to learn how to do this work right" (p. 175). And isn't helping students get to that point the mission of education in the first place? 


\section{References}

Allemand, K. (2012). Student and Faculty Perceptions of Academic Dishonesty: A Qualitative Single-Case Study. Northcentral University.

Arnold, R., Martin, B. N., \& Bigby, L. (2007). Is there a relationship between honor codes and academic dishonesty? Journal of College and Character, 8(2), 1-20.

Beasley, E.M. (2016) Comparing the demographics of students reported for academic dishonesty to those of the overall student population. Ethics \& Behavior 26(1), 45-62.

Blum, S.D. (2009) My Word! Plagiarism and College Culture. Cornell University Press.

Bowers, W. J. (1964). Student dishonesty and its control in college. Bureau of Applied Social Research, Columbia University.

Chace, W. M. (2012). A question of honor. American Scholar, 81(2), 20-32.

Hamlen, K. R. (2012). Academic dishonesty and video game play: Is new media use changing conceptions of cheating? Computers \& Education, 59(4), 1145-1152.

Helgeson, K. M. (2002). Perceptions of academic dishonesty among students and faculty at the University of Nebraska-Lincoln. University of Nebraska--Lincoln.

Kibler, W. L., \& Kibler, P. V. (1993). When Students Resort to Cheating. The Chronicle of Higher Education. https://www.chronicle.com/article/When-Students-Resort-to/70647

McCabe, D. L., Trevino, L. K., \& Butterfield, K. D. (2001). Cheating in Academic Institutions: A Decade of Research. Ethics \& Behavior, 11(3), 219-232.

McCabe, D. L., \& Trevino, L. K. (1996). What We Know About Cheating In College Longitudinal Trends and Recent Developments. Change: The Magazine of Higher Learning, 28(1), 28-33. https://doi.org/10.1080/00091383.1996.10544253

Sledge, S., \& Pringle, P. (2010). Assessing honor code effectiveness: Results of a multipronged approach from a five year study. Research \& Practice in Assessment, 5.

Tavris, C., \& Aronson, E. (2020). Mistakes were made (but not by me) third edition: Why we justify foolish beliefs, bad decisions, and hurtful acts. Houghton Mifflin Harcourt. 
THE NEBRASKA EDUCATOR, VOLUME 5

Wideman, M. (2011). Caring or collusion? Academic dishonesty in a school of nursing. Canadian Journal of Higher Education, 41(2). 